\title{
Liposarcoma of the pleural cavity. An exceptional tumour
}

\author{
A. Minniti1, M. Montaundon2, J. Jougon1, M. Hourneau1, \\ H. Begueret ${ }^{3}$, F. Laurent', J-F. Velly ${ }^{1}$
}

ABSTRACT: Liposarcoma of the pleural cavity. An exceptional tumour. A. Minniti, M. Montaundon, J. Jougon, M. Hourneau, H. Begueret, F. Laurent, J-F. Velly.

Primitive liposarcomas of the pleura are exceptional tumours. We report a new case of primitive liposarcoma of the pleura revealed by chest pains in a 50 year old man.
Computed tomography showed a large fat density mass in the left pleural cavity. Surgical resection was performed, completed with adjuvant radiotherapy.

Few reports are available in the literary world. We present our case, review previously reported cases and discuss treatment.

Monaldi Arch Chest Dis 2005; 63: 3, 170-172.

Keywords: Liposarcoma, pleura, tumor, computed tomography, surgery, radiotherapy.

1 Department of Thoracic Surgery,

2 Department of Radiology,

3 Department of Pathology, Haut-Lévêque Hospital, Bordeaux, France.

Correspondence: Dr. Antonio Minniti, Department of Thoracic Surgery, University of Bordeaux, MHL Haut-Lévêque Hospital, 33604 Pessac; e-mail: minniti_ant@hotmail.com

\section{Introduction}

Primary liposarcomas of the pleura are rare diseases. Liposarcoma most commonly arises in the retroperitoneum or thigh, but also in the inguinal area, paratesticular region, arm, neck, shoulder, and scalp. Primitive intrathoracic liposarcomas are usually located in the mediastinum or in lung parenchyma. Primitive liposarcomas of the pleura are exceptional and only few cases have been reported in international literature [1-2-3].

We report, herein, an additional case.

\section{Case Report}

In December 2003, a 50 year-old man was referred to us with left thoracic pain, asthenia and dyspnoea, correlated to a lower posterior mediastinal mass, showed by the chest roentgenogram.His past medical history contained details of a a trauma to the chest caused by a road accident. He was a non-smoker.The CT-scan showed a voluminous mass of the posterior mediastinum, $13 \times 10 \mathrm{~cm}$ of diameter (fig. 1-2).

The CT-scan was interpreted as recurrent left diaphragmatic hernia or lower benign pleural tumour. Spirometry, fibrobronchoscopy and pulmonary scintigraphy were normal, as well as the blood gas analysis examination.

Blood pressure was of $135 / 70 \mathrm{~mm} \mathrm{Hg}$ and pulse rate of $110 /$ minute. Temperature was $37.3^{\circ} \mathrm{C}$. Laboratory studies revealed a leucocytes count of $16,000 / \mathrm{ml}$ and a haemoglobin level of $12 \mathrm{~g} / \mathrm{dl}$.
To rule out a diaphragmatic hernia a pneumoperitoneum was realised, showing a normal aspect of the diaphragm below the tumour. Other examinations (bone scan, abdominal CT) were normal.

Based on the result of this examinations, a decision to carry out a surgical excision was taken.

A left thoracotomy was performed. A regular fatty tumour with an important adhesion to the diaphragm was discovered (fig. 3) during surgical exploration. There was no infiltration of the vascular structures. Resection was radical. The postoperative course was uneventful and the patient was discharged on the sixth post-operative day.

Microscopic findings concluded to a well differentiated lipoma-like pleural liposarcoma of $13 \mathrm{x}$ $12 \times 6 \mathrm{~cm}$, grade 1 according to the FNCLCC grading system (Federation national de centre de lutte contre le cancer).

Adjuvant post-operative radiotherapy of the pleura was decided. He underwent a irradiation of 46,8 Gy; he was free from the disease with 12 months of follow-up.

\section{Discussion}

Including the case reported herein, a total of 16 cases of primary liposarcomas of the pleura have been described in international literature today [12-3]. These cases included 10 men and 6 women. The age at manifestation ranged from 19 to 80 years, with an average of 51 years.

The most common initial symptoms were cough, dyspnoea, chest pain, shortness of breath, 

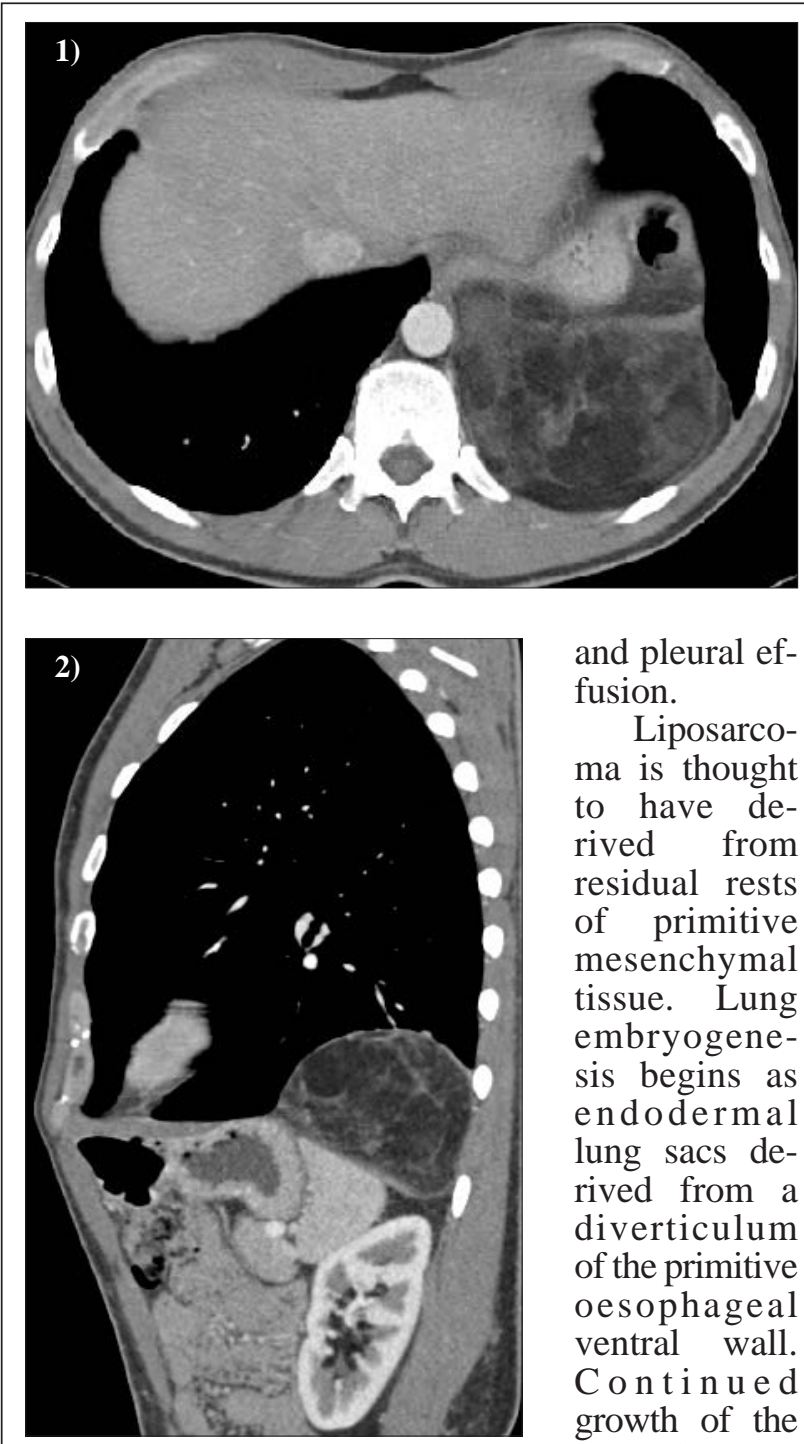

Fig. 1, 2. - Computed tomographic scan of the chest, showing a mass in the left pleural cavity. as the lungs expand. The pleural cavity forms from the mesoderm-derived chest wall, and its inner mesothelial lining is continuous with the pleura [4].

During this process, residual mesenchymal tissue may undergo malignant transformation, giving rise to pleural liposarcoma [2].

Liposarcomas arising in a pre-existing lipoma is extremely rare, and there are only few possible cases in literature. Well-differentiated lipoma-like liposarcomas are likely to be mistaken for a lipoma.

Histologically four sub-categories exist that generally reflect the degree of differentiation [5]:

- well differentiated, subclassified as,

1 - lipoma-like,

2 - sclerosing;

- myxoid;

- dedifferentiated;

- pleomorphic.

The well differentiated and the myxoid subtype are the most common. Primary liposarcomas of the pleura are usually bulky. Median measures are 19 $\mathrm{cm}$ (extreme 2.5 to $29 \mathrm{~cm}$ ). The weight of the reported tumours ranged from 0.9 to $4.4 \mathrm{~kg}$ [3]. The most common metastatic sites are lung and bone [1].
A case of relapse two years after excision of the primary tumour is described, but the histological characteristic resembled a malignant fibrous histiocytoma [6].

Differential diagnoses include solitary fibrous tumour of the pleura, mesothelioma, bronchogenic carcinoma, benign fatty tumours, abscess. Due to the co-existence of fat and soft tissue, liposarcomas appear as well-defined masses of inhomogeneous fat attenuation at CT. The attenuation value depends on the presence or absence of islands of soft tissue and is usually greater than -50 HU [7]. At MRI, liposarcomas demonstrate a high intensity signal on T1 and T2spin echo sequences and a low intensity signal when using fat suppression sequences. Dedifferentiated and pleiomorphic liposarcomas may not show any visible fatty component. Enhancement of soft tissue may be seen after intravenous contrast material administration.

The rarity of liposarcoma arising from the pleural cavity makes difficult to predict treatment outcomes.According to the review of Wong et al [1] the treatment of choice is radical surgical excision and adjuvant irradiation. In the sixteen cases reported, fourteen received treatment.

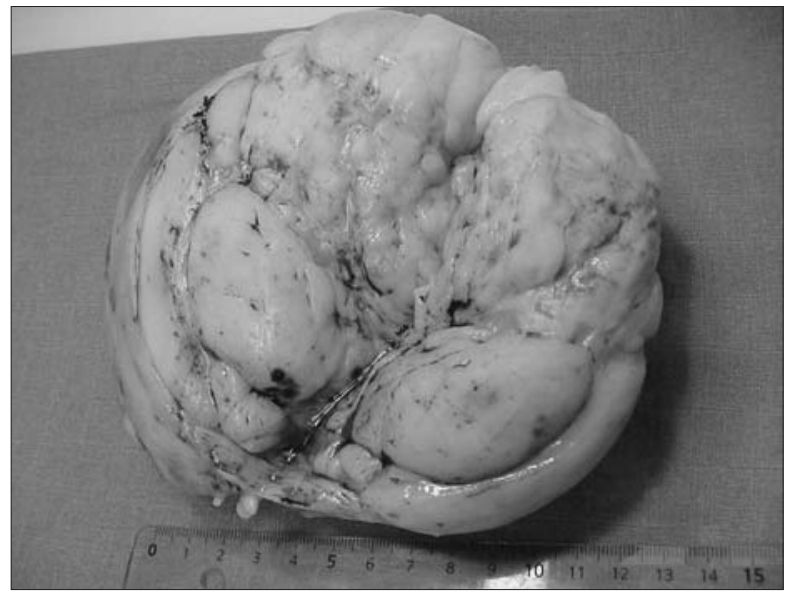

Fig. 3. - Well-demarcated lipomatous yellow tumour.

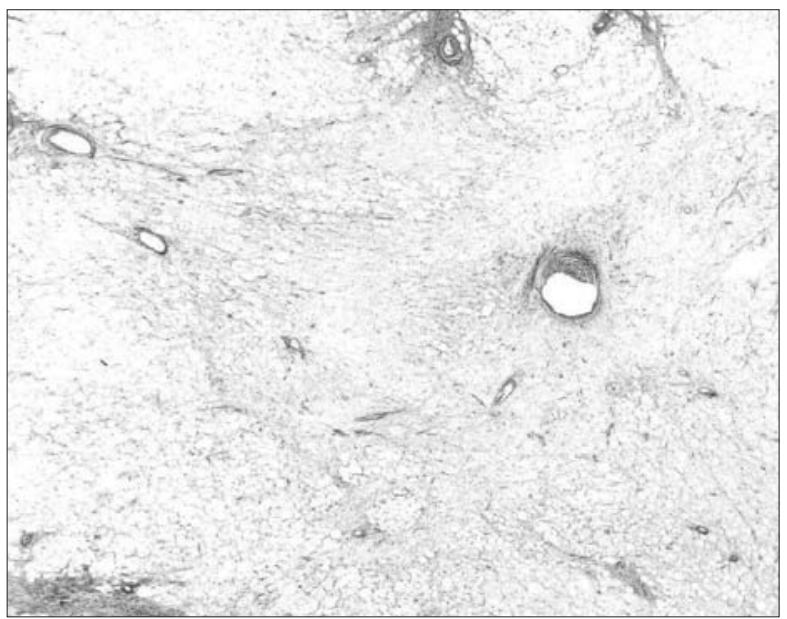

Fig. 4. - Mature-appearing adipose tissue with loose sclerotic intervening fibrous tissue and scattered inflammation (haematoxylineosin, original magnification $\mathrm{x} 40$ ). 
Six patients underwent only surgical operations; two were alive at 5,5 years and 34 months, respectively, one was lost.

Five patients underwent an operation and adjuvant irradiation; all patients were alive. One patient had local recurrence 4 years after surgical operation and postoperative irradiation of $20 \mathrm{~Gy}$; he underwent a salvage operation and irradiation of 50 Gy for the recurrent disease; he was free of disease 4 years after undergoing treatment for the recurrence [1].

Chemotherapy in one case in association with surgical resection, in another case in association with surgical resection and radiotherapy did not appear to be effective (patients died respectively at 7 and 16 months). One patient received only palliative care; he died 9 months after initial diagnosis.

Therefore 7 patients (50\%) are alive.

In conclusion, primary liposarcoma of the pleura are unusual tumours. The rarity makes it difficult to identify the prognostic factors that correlate with survival.
Based on international literature, surgical resection followed by adjuvant radiotherapy appears to be the treatment of choice.

\section{References}

1. Wong WW, Pluth JR, Grado GL, Schild SE, Sanderson DR. Liposarcoma of the pleura. Mayo Clin Proc 1994; 69: 882-885.

2. Okby NT, Travis WD. Liposarcoma of the pleural cavity: clinical and pathologic features of 4 cases with a review of the literature. Arch Pathol Lab Med 2000; 124: 699-703.

3. Hofman V, Venissac N, Mouroux J, Dugue P, Hofman P. Liposarcome de la plèvre: une tumeur exceptionnelle. Ann Pathol 2003; 332-5.

4. Moore KL ed. The developing human clinically oriented embryology. Philadelphia, Pa: WB Saunders; 1988.

5. Eizenger FM, Weiss SW eds: Soft tissue tumors. St Louis, Mo: Mosby-Year Book; 1995.

6. McGregor DH, Dixon AY, Moral L, Kanabe S. Liposarcoma of pleural cavity with recurrence as malignant fibrous histiocytoma. Ann Clin Lab Sci 1987; 17: 83-92.

7. Bonomo L, Feragalli B, Sacco R, et al. Malignant pleural disease. Primary intrathoracic malignant mesenchymal tumors: pictorial essay. Eur J Radiol 2000; 34 (2): 98-118.

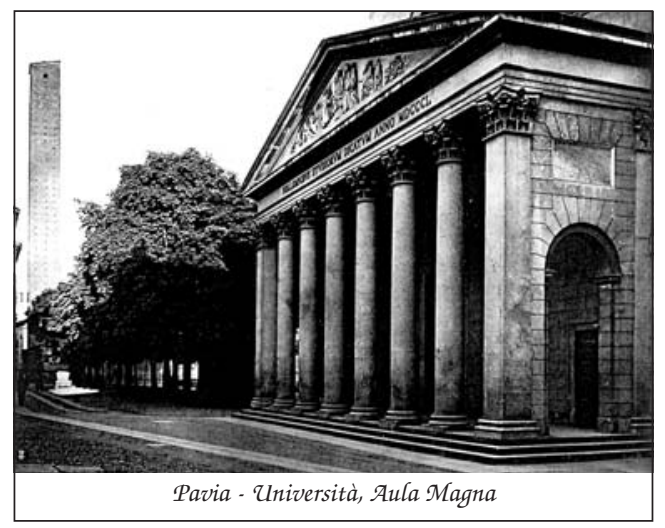

